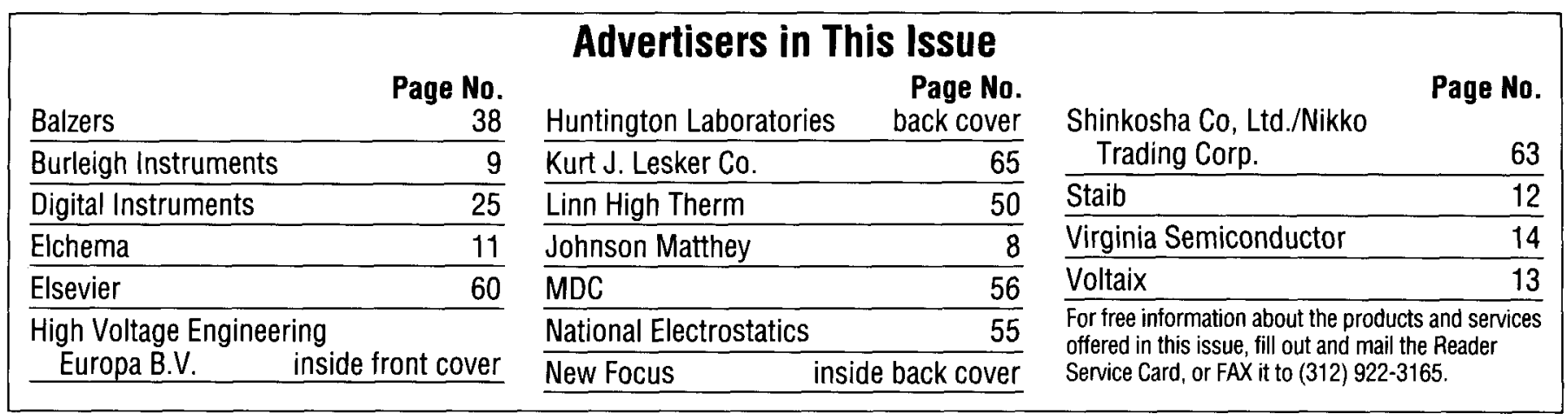

\title{
POSTERMINARIES
}

\section{More SAGE Advice}

MRS Bulletin: It's been some time since we last chatted, Dr. Sage. Do you have any new insights to share with us?

Dr. Science I.M. Sage: Actually, yes. I'm sure you're aware of the recent trend in the U.S. Congress to direct research dollars into strategic areas and of the kneejerk defensive reaction of our basic research community.

MRSB: We have been watching the legislative process with great interest and trying to keep up with the responses of agencies and universities. How do you think this will all come out in the end?

Dr. SIMS: It's not the end everyone is worried about. It's the beginning-how many dollars will come out in the beginning of the next fiscal year. But in my humble opinion, I don't think there's much to worry about. Remember, we're talking about the distinction between socalled "curiosity-driven" research and "basic" research in strategic areas related to identifiable national goals. The underlying creative process will remain unscathed.

MRSB: How can you reach that conclusion? How can you say that the creativity of a basic follow-your-nose researcher will not be squelched by congressional directives to work on this but not on that?

Dr. SIMS: Once again I have overestimated your ability to grasp the most trivial concepts. Let me spell it out for you. Creativity is a phenomenon like a hallucination. Try as they might, higher authorities can no more legislate it out of existence than they could make madness illegal. I commend to you an excellent summary of the long-established relationship between creativity and madness that was published in the Orange County Edition of the Los Angeles Times on April 21, 1987 (a Tuesday, if memory serves). Both creativity and madness are simply uncontrollable departures from normality.

MRSB: How in the Annals of Psychology Today does this lead you to any useful conclusion?

Dr. SIMS: Of course, too large a departure from normal lands you in a facility for the terminally creative. But I consider myself to be as creative as one can be without being hauled off for the greater good. You would be well-advised to follow my example in the face of the new strategic research ethos.

MRSB: Please elaborate.

Dr. SIMS: O.K. Most of my flashes of insight come to me in the shower or in the nether world between waking and sleep. To date, these have been curiosity-driven insights, and in my pursuing them, serendipitous amplifications have often increased the value of the original flash. Now, all I must do is take strategic showers and read a good strategic book, like $A$ Brief History of Environmentally Benign Manufacturing of Biodegradable Microelectronic Devices instead of $A$ Brief History of Time, before dropping off to sleep. Our incredible subconscious processors (well, mine is incredible) will automatically produce strategic insights. These will be dual-use insights, relevant to my innate interests but distorted sufficiently toward national goals to secure my funding. In fact, you might call this process, "serendouble-dipity."

MRSB: I think we get the drift, but what, pray tell, is a strategic shower?

Dr. SIMS: It could mean many things to many people, but for me it means lower- ing the water temperature to near freezing. You see, it requires great planning and strategy to negotiate such a shower from entry to exit. This produces a mindset that sloshes the creative juices (at least those not yet frozen) in the right direction. And as a corollary benefit, it builds resistance to just the kind of chill on the creative process that everyone is worried about.

MRSB: At the risk of offending you, Dr. Sage, we must ask if you are spoofing us, or if you are making serious recommendations?

Dr. SIMS: Don't worry, I can only be offended by my peers, and they are few and far between. In fact, I haven't encountered one in quite a while. Ever since I began experimenting with the muchtouted peer-review process and found, on review, that many of my peers didn't measure up, their numbers have dwindled. But I digress. I spoof you not. You must, however, interpret my recommendations as more parable than practical.

MRSB: Oh, sorry! We certainly apologize for not recognizing allegory when it's staring us in the face. We suppose our readers will know instinctively how to apply this lesson to their daily lives.

Dr. SIMS: Indeed they should. Unfortunately, those who are too literal in their outlook on life believe strategic really means strategic and will be caught reading in the shower. As they are carted off to join their overly creative counterparts, we can take solace from knowing that each such departure equates to a job opening for the up-and-coming new generation of researchers who think "knowledge for knowledge's sake" is a quaint idiom employed by relics of a bygone era.

E.N. KAUFMANN 